\title{
Automated methods for detecting lameness and measuring analgesia in dairy cattle
}

\author{
N. Chapinal, ${ }^{\star 1}$ A. M. de Passillé, $†$ J. Rushen,, and S. Wagnerł \\ *Animal Welfare Program, University of British Columbia, 2357 Main Mall, Vancouver, BC, V6T 1Z4, Canada \\ †Agriculture and Agri-Food Canada, PO Box 1000, Agassiz, BC, V0M 1A0, Canada \\ fDepartment of Animal Sciences, PO Box 6050, North Dakota State University, Fargo 58108
}

\section{ABSTRACT}

The objective was to assess gait, automated measures of weight distribution among the legs, and daily activity as methods for detecting lameness in dairy cows and measuring pain mitigation by nonsteroidal antiinflammatory drugs. Fifty-seven lactating cows (28 of which were lame) were injected twice with ketoprofen $(3.0 \mathrm{mg} / \mathrm{kg}$ i.m. $)$ or isotonic saline solution. Gait scores (numerical rating system, NRS), time spent lying down, frequency of steps, and weight distribution among legs when standing before, during, and after injections were measured to assess whether automated measures of activity can detect lameness and the effect of analgesic drugs in cows. Lame cows (NRS $>3$ ) shifted weight between contralateral legs more often (SD of the weight applied: $31.1 \pm 2.1$ vs. $24.5 \pm 1.9$ $\mathrm{kg}$ ), had a greater asymmetry in the weight applied to the rear legs (leg weight ratio $=0.78 \pm 0.02$ vs. $0.87 \pm$ $0.02)$, had longer lying bouts $(94.0 \pm 4.9$ vs. $78.2 \pm 5.8$ $\mathrm{min})$, and walked slower (1.28 \pm 0.3 vs. $1.42 \pm 0.3 \mathrm{~m} / \mathrm{s})$ than nonlame cows. Variability over time (SD) of the weight applied to the rear legs was the most accurate predictor of whether a cow was lame or not (area under the curve $=0.71$ ). The SD of the weight applied to the rear legs decreased on the days when ketoprofen was given compared with the day before and after (18 and $12 \%$ decrease for lame and nonlame cows, respectively). Ketoprofen did not affect any other measure. Measures of weight shifting between legs while cows are standing have potential as an automated method of detecting lameness and analgesia.

Key words: lameness, ketoprofen, weight distribution, lying behavior

\section{INTRODUCTION}

Lameness in dairy cows is a painful condition that decreases productivity and impairs animal well-being (Rushen et al., 2008). Difficulty in detecting lameness

Received October 6, 2009

Accepted January 18, 2010.

${ }^{1}$ Corresponding author: nchapinal@yahoo.com on large farms (Espejo and Endres, 2007) has led to interest in improved methods of detecting lameness, especially automated methods. In previous studies, lameness in cows resulted in a change in weight distribution among legs when standing (Pastell and Kujala, 2007), increased lying time (O'Callaghan et al., 2003; Chapinal et al., 2009b), or reduced mobility (Borderas et al., 2008). These behavioral changes can be monitored automatically.

Changes in gait among lame cows are caused by the pain resulting from lesions primarily in the hooves (Whay et al., 1998). Rushen et al. (2007) observed that injection of lidocaine, a local anesthetic, into the bulb of an injured hoof resulted in a moderate gait improvement, increased the proportion of weight applied to the injured hoof, and decreased the frequency of weight shifting between the injured leg and the contralateral leg. In contrast, the effects of nonsteroidal antiinflammatory drugs (NSAID), such as ketoprofen, are less clear. Despite successful treatment of lameness in horses (Owens et al., 1995), the use of ketoprofen resulted in either moderate (Flower et al., 2008) or no improvement (Whay et al., 2005) in the gait scores of dairy cows. It is possible that gait scoring is not sensitive enough to detect the effects of analgesic drugs: Rushen et al. (2007) found a greater effect of local anesthetic injection on measures of weight distribution than on gait scores. Thus, a combination of measures of lameness, such as measures of weight distribution (Pastell and Kujala, 2007; Rushen et al., 2007) or activity (Chapinal et al., 2009b) may be necessary to detect the effect of analgesic drugs on lameness in dairy cows. The objective was to assess gait, automated measures of weight distribution among the legs, and daily activity as methods for a) detecting lameness in dairy cows, and b) measuring pain mitigation by NSAID treatment.

\section{MATERIALS AND METHODS}

\section{Animals and Housing}

Multiparous lactating Holstein cows $(\mathrm{n}=57$; mean $\pm \mathrm{SD}$; parity $=3.7 \pm 1.8 ; \mathrm{BW}=719 \pm 63 \mathrm{~kg} ; \mathrm{DIM}=$ 
$196 \pm 98 ; 305$-d milk production $=12,230 \pm 1,457 \mathrm{~kg}$ ) were selected from the herd at the University of British Columbia's Dairy Education and Research center in Agassiz, Canada. Cows were housed in sand-bedded freestalls $(2.4 \mathrm{~m}$ long $\times 1.18 \mathrm{~m}$ wide $\times 0.40 \mathrm{~m}$ deep, at least 1 stall per cow) in groups of 24 to 48 cows per pen. Cows were fed a TMR diet available ad libitum with fresh feed delivered twice daily at 0700 and 1600 $\mathrm{h}$, formulated to meet requirements for lactating dairy cows (NRC, 2001). Water was freely available from self-filling troughs. Cows were milked twice daily in the parlor at approximately 0800 and $1700 \mathrm{~h}$. The experimental protocol was approved by the Institutional Animal Care Committee, which is monitored by the Canadian Council on Animal Care. The experiment was conducted between February and May 2009.

\section{Experimental Procedure and Treatments}

During 9 wk, a subset of at least 6 animals per week was selected from 4 different pens. The day before treatments were applied, cows were gait-scored using the method described below. Each animal was assigned to either ketoprofen (Anafen, Merial Canada Inc., Montreal, Canada) or sterile isotonic saline (control) treatment, such that treatments groups were balanced according to initial gait score (numerical rating system; NRS $=3.1 \pm 0.6$ and $3.2 \pm 0.7$, for the saline and ketoprofen cows, respectively), BW, parity, and DIM. Three severely lame animals (NRS $=4.5$ ) were assigned to the ketoprofen treatment for moral reasons.

On 2 consecutive days, cows were held in a headlock one at a time after the morning milking (between 0800 and $1100 \mathrm{~h}, \sim 0.5 \mathrm{~h}$ between cows) and injected i.m. in the neck with a dose of $3.0 \mathrm{mg} / \mathrm{kg}$ of BW of ketoprofen or the equivalent volume of saline solution. Volumes ranged from 18 to $27 \mathrm{~mL}$. Half the volume was injected on each side of the neck. Two hours after the injection, cows were gait-scored and measures of weight distribution were taken in a designated area as described below. Data collection lasted approximately $20 \mathrm{~min}$ for each animal.

Nonsteroidal antiinflammatory drugs have both central and peripheral analgesic effects and the drugs accumulate and persist at sites of inflammation (Lees et al., 2004). Ketoprofen was administered for $2 \mathrm{~d}$ at a 24-h interval to maximize the likelihood of achieving effective local drug concentrations (persisting from the first dose) and effective systemic drug concentrations (from the second dose) simultaneously, thus improving the ability to provide detectable analgesia in lame cows.

\section{Data Collection}

Gait Score. The cows had their gait scored at a fixed time of the day, on the day before ketoprofen treatment, on the $2 \mathrm{~d}$ of treatment $(2 \mathrm{~h}$ after the injection), and on the day after treatment, while walking down a 13-m-long $\times 1$ 1.3-m-wide nongrooved concrete passageway after the morning milking. To encourage cows to walk in a consistent manner, a handler walked immediately behind the cows encouraging them when necessary down the passageway. Cows were habituated to the procedure over at least $4 \mathrm{~d}$ (4 passages/d) before the first gait-scoring event. On each data collection day, each cow was videotaped during each of her 5 passages her left side by using a color digital camera (Sony DCRSR100 HDD Handycam Camcorder; Sony Corp., Park Ridge, NJ; 30 frames/s) connected to a digital recording system (Genetec Inc., Saint-Laurent, Quebec, Canada) placed $8 \mathrm{~m}$ from the cow to allow recording of at least 4 complete strides during each passage. Specialized software was used to review the video data (Omnicast, Genetec Inc.). One experienced observer watched the videos and assigned a gait score to each cow for each day using a 1 to 5 numerical rating system (where 1 = perfect gait and $5=$ severely lame) with half-integer scores (Flower and Weary, 2006; Chapinal et al., 2009b).

Walking Speed. The walking speed of the cows was measured using the same video recordings as for the gait scoring. Two marks separated by $9.35 \mathrm{~m}$ were painted on the floor and walls of the passageway and the time was calculated between when the nose of the cow was aligned with the starting and end marks using specialized software (Omnicast Archive Player, version 4.2, Genetec Inc.).

Weighing Platform. Measures of how the cows distributed their weight between their legs while standing were measured using the method described in Neveux et al. (2006) and Chapinal et al. (2009a). This was done at a fixed time of day, on the day before treatment, on the $2 \mathrm{~d}$ of treatment ( $2 \mathrm{~h}$ after the injection), and on the day after treatment.

The distribution of weight among the legs was measured while cows were standing on a weighing platform (Pacific Industrial Scale Co. Ltd., Richmond, British Columbia, Canada) situated at the end of the passageway used for gait scoring. The platform contained 4 stainless steel independent recording units $(12 \mathrm{~cm}$ high $\times 59 \mathrm{~cm}$ wide $\times 99 \mathrm{~cm}$ long) covered with $1.5-\mathrm{cm}-$ thick revulcanized rubber mats (Animat, Saint-Élie d'Orford, Quebec, Canada). Each recording unit contained 4 stainless steel, hermetically sealed load cells (3 
$\mathrm{mV}$ Shear Beam Load cells, Anyload LLC, Santa Rosa, $\mathrm{CA}$; maximum capacity $=454 \mathrm{~kg}$ each load cell). The weights were unaffected by the position of the hooves on the units. Data were transmitted to a computer at a rate of 14 readings/s. Specific software (CowWeigh.exe version 2.2, Pacific Industrial Scale Co. Ltd.) provided a real-time display of the weight applied to each of the 4 units. The platform was lifted $4.5 \mathrm{~cm}$ from the floor with concrete blocks to avoid load cell corrosion due to humidity. A manual steel squeeze chute $(2.1 \mathrm{~m}$ high, $2.0 \mathrm{~m}$ long, 1.3 wide) was mounted on the platform to restrain the cows.

Cows were familiarized with the platform and the procedure by standing on the platform 4 times/d for at least $4 \mathrm{~d}$ before data were collected. On data collection days, cows stood on the platform for 5 min after each of the last 3 walking passages. When hooves were not on the appropriate recording unit, the cow was gently manipulated to encourage repositioning.

Activity. Three days before treatment started, the cows were fitted with accelerometers (Ice Tag, IceRobotics, Edinburgh, UK) to continuously record activity over $10 \mathrm{~d}$ (Munksgaard et al., 2006). The accelerometer was attached by means of a strap to the right hind leg above the fetlock. In cases when signs of inflammation were present in the right hind leg, the device was attached to the left hind leg. The accelerometers recorded the number of steps, the duration of lying/standing bouts, and the total time spent lying and standing per day. The accelerometers provided information on the position of the cow (lying or standing) based on 16 reading/s.

Clinical Examination of the Hooves. Hooves were examined 1 to $2 \mathrm{wk}$ after treatment. The soles of the hooves were pared minimally by a trained hoof trimmer to expose a clean surface. An experienced observer examined the front and rear hooves of the cows and recorded the presence, location, and severity of sole hemorrhages, sole ulcers, and digital dermatitis, following the method described in Chapinal et al. (2009b). One of lame cows (belonging to the saline treatment group) presented an ulcer, and 15 cows (9 in the saline treatment and 6 in the ketoprofen treatment) had mild cases of digital dermatitis.

\section{Data and Statistical Analysis}

All statistical analyses were performed with SAS software (version 9.1; SAS Institute, 2003) using the cow as the experimental unit. Lameness status was determined according to the NRS assigned to cows the day before ketoprofen treatment. Cows were classified as lame if initial NRS $>3$ (Flower and Weary, 2006; Chapinal et al., 2009b). A total of 28 cows were classified as lame (13 in the saline treatment and 15 in the ketoprofen treatment).

Readings from the weighing platform in which the total weight recorded was $5 \%$ above or below the mode of the total weight within the passage were discarded. Readings from each passage were summarized to obtain the mean weight applied on each leg. Data for each pair of legs (front or rear) were averaged by day and animal for the analysis. In addition, 2 more variables that were suggested indicators of lameness were used: a) the standard deviation (SD) of the weight applied on each leg over the 5-min period as a measure of leg-load variability or weight shifting between legs (Rushen et al., 2007), and b) the leg weight ratio (LWR) between the lighter and the heavier leg of the front pair and of the rear pair of legs, as a measure of asymmetry within each pair of legs (Pastell and Kujala, 2007). Data from the weighing platform were not available for d 2 to 4 for 7 cows because of technical problems in the third week of the experiment.

For the analysis of activity data, a day was defined as the 24 -h period starting at the time of the first injection. On the days when cows were injected, animals were noticeably disturbed by the data collection procedures during the $3 \mathrm{~h}$ following the injections. Therefore, the first $3 \mathrm{~h}$ of each $24 \mathrm{~h}$ were removed for the final analysis. Data were averaged by period: before treatment ( $3 \mathrm{~d})$, during treatment $(2 \mathrm{~d})$, and after treatment $(4 \mathrm{~d})$. Activity data from 5 cows were not used: 2 cows showed estrus that altered their activity pattern, 1 of the severely lame cows was kept in an individual pen, which limited her movements, and accelerometers failed to record data in 2 occasions.

A mixed model (PROC MIXED; SAS Institute, 2003) that included cow as a random effect, treatment (saline or ketoprofen) and group (week of test) as factors, day relative to treatment as a repeated measure, and the pairwise interactions was used to test differences in NRS in response to treatment. Contrast statements were used to test the day before and after treatment against the $2 \mathrm{~d}$ of treatment within each treatment. Residuals were examined to verify normality and homogeneity of variances. A similar mixed model that included lameness status was used to test differences in walking speed, the SD applied to each pair of legs, the front and rear LWR, and activity (lying behavior and steps) in response to treatment. For activity measures, the period relative to ketoprofen treatment was considered as the repeated measure instead of the actual day. Analyses were performed with and without the severely 
lame cows $(\mathrm{NRS}=4.5)$, but because the results were very similar, only results from the analyses including all the cows are shown.

To examine the effect of lameness independent of ketoprofen treatment, data collected before treatment were used to perform a multivariate logistic regression (PROC LOGISTIC) to determine the predictive value of the weight distribution variables, activity, and walking speed on whether or not the cow was classified as lame. Logistic models were used first to fit one variable at a time. Variables with $P<0.05$ were used to construct a complete logistic model. Correlation between variables was assessed (PROC CORR) to avoid including highly related variables in the same model. Receiver operating characteristics curves were plotted and the area under the curve (AUC) was used to compare the accuracy of the different models in discriminating lame cows.

\section{RESULTS}

\section{Gait Score and Walking Speed}

Lame cows walked slower than nonlame cows $(1.28 \pm$ 0.03 vs. $1.42 \pm 0.03 \mathrm{~m} / \mathrm{s} ; P=0.004)$. Overall, there was no significant effect of ketoprofen treatment on NRS or walking speed (treatment and treatment $\times$ day $P>0.2$ in all cases). The NRS did not change over days $(P>$ $0.10)$. However, walking speed decreased over days for both treatments from the day before the first injection to the day after the second injection (from $1.40 \pm 0.03$ to $1.24 \pm 0.03 \mathrm{~m} / \mathrm{s} ; P<0.001)$.

\section{Weight Distribution}

Overall, lame cows had a higher SD of weight applied to the rear legs $(31.1 \pm 2.1$ vs. $24.5 \pm 1.9 \mathrm{~kg}, P=0.02)$ and a higher SD of weight applied to the front legs $(19.5 \pm 1.2$ vs. $16.1 \pm 1.1, P=0.05)$ than nonlame cows. The SD of the weight applied to the rear legs improved after the ketoprofen injections, but not after the saline injections $(P=0.003$ for the treatment $\times$ day interaction; Figure 1). The SD of weight applied to the rear legs decreased on the days when the ketoprofen injections were given compared with the days before and after for both lame and nonlame cows (18\% and $12 \%$ respectively; $P=0.0003)$. The $\mathrm{SD}$ of the weight applied to the front legs did not decrease after treatment $(P=0.84)$.

Generally, lame cows showed more weight asymmetry between the rear legs than nonlame cows $(\mathrm{LWR}=0.78$ \pm 0.02 vs. $0.87 \pm 0.02, P=0.003)$, but did not differ from nonlame cows in the asymmetry of weight between front legs $(L W R=0.87 \pm 0.02$ vs. $0.85 \pm 0.01)$. There was no effect of ketoprofen treatment $(P>0.4$ in all cases) on the LWR of either the front or rear legs.

\section{Activity}

Overall, lame cows tended to spend more time lying down $(11.1 \pm 0.4$ vs. $10.3 \pm 0.3 \mathrm{~h} / 21 \mathrm{~h} ; P=0.08)$ because of longer lying bouts $(94.0 \pm 4.9$ vs. $78.2 \pm 5.8$ $\min ; P=0.03)$. There was no effect of lameness on frequency of lying bouts $(8.2 \pm 0.4$ vs. $8.1 \pm 0.4$ bouts $/ 21$ h; $P=0.83)$ or the number of steps taken $(1,256 \pm 73$ vs. $1,320 \pm 86$ steps $/ 21 \mathrm{~h}$ for lame and nonlame cows, respectively; $P=0.65$ ). There was no significant effect of ketoprofen treatment on the time cows spent lying down, the frequency of lying bouts or their duration, or the frequency of steps $(P>0.10)$.

\section{Logistic Regression}

The initial logistic regression showed that the SD of weight applied to the rear legs, the SD of weight applied to the front legs, the LWR of the rear legs, the daily duration of time spent lying down, the average duration of the lying bout, and walking speed were associated (or tended to be associated) with the occurrence of lameness (Table 1). The daily lying time and the duration of the lying bouts were correlated $(\mathrm{r}=0.28, P$ $=0.04$ ) and therefore, only the duration of lying bouts was included in the final model because it was more strongly associated with an increased likelihood of being lame. The SD of the rear legs was correlated to the SD of the front legs $(\mathrm{r}=0.52, P<0.001)$ and to the LWR of the rear legs $(\mathrm{r}=-0.37, P=0.004)$; therefore, the 3 weight distribution variables were included in 3 different models that included the average duration of the lying bouts and walking speed. The best predictive model (i.e., with the greatest AUC) with a single predictor for lameness was the one that included the SD of the weight applied to the rear legs. The AUC increased from 0.71 to 0.76 after adding the average duration of the lying bout, and to 0.83 after adding both the average duration of lying bout and walking speed (Figure 2 ). The model including the SD of the weight applied to the rear legs and the mean duration of lying bouts accounted for $29 \%$ of the variation in likelihood of a cow being lame $\left(P_{\text {Wald }}=0.02 ; \mathrm{R}^{2}=0.29\right)$, whereas the model that also included walking speed accounted for $35 \%$ of the variation in the likelihood of lameness $\left(P_{\text {Wald }}\right.$ $=0.03 ; \mathrm{R}^{2}=0.35$ ).

\section{DISCUSSION}

Measures of weight distribution show promise as an automated method to detect lameness on the farm, especially in association with measures of activity and walking speed. The effects of ketoprofen were apparent in the shifting of weight between legs, but the magni- 

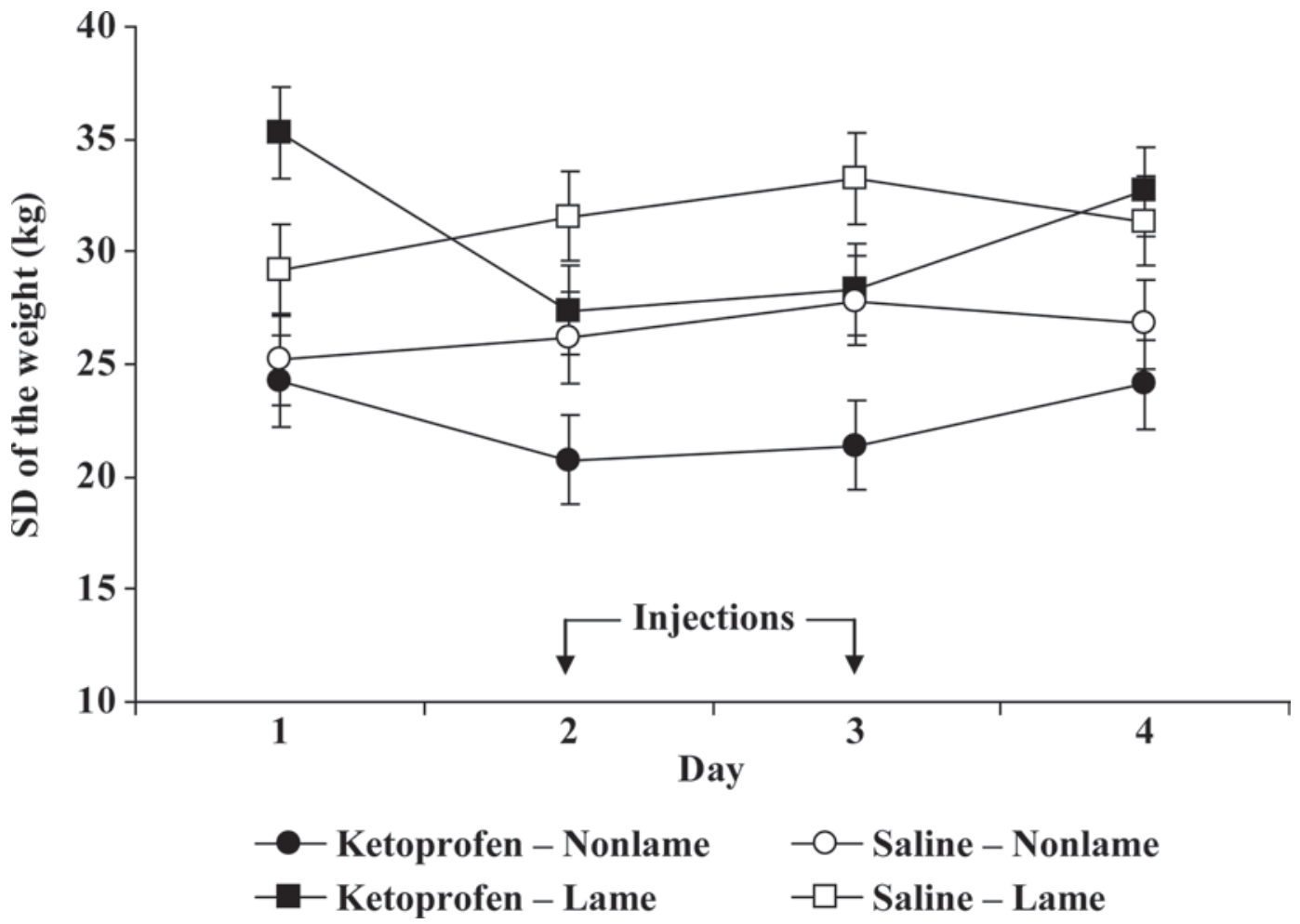

Figure 1. Mean $( \pm \mathrm{SE})$ variability over time $(\mathrm{SD})$ of the weight applied to the rear legs in 50 cows injected with ketoprofen or a saline solution on the day before the injections (d 1), the days when treatments were applied ( 2 and 3 ) and the day after the injections (d 4). Cows were classified as lame (numerical rating system, NRS $>3 ; 13$ in the saline treatment and 12 in the ketoprofen treatment) or nonlame (13 in the saline treatment and 12 in the ketoprofen treatment). $(P=0.0003$ when d 2 and 3 were tested against d 1 and 4 in the case of cows treated with ketoprofen).

tude of this effect was modest. There was no effect of ketoprofen on gait scores, walking speed, or activity. These results suggest that weight distribution measures were more sensitive than gait scores as methods to evaluate the effect of ketoprofen (Whay et al., 2005; Flower et al., 2008).

The NRS did not improve after ketoprofen injection, supporting the results of Whay et al. (2005). Flower et al. (2008) reported a moderate reduction in NRS after ketoprofen (0.25 units), similar to the reduction reported by Rushen et al. (2007; 0.3 units) after injection of the hoof bulbs with lidocaine. In both cases, the reduction was similar to the resolution of the scoring system (0.5 units) and therefore, caution is required in the interpretation of the results. Whay et al. (2005) found no effect of ketoprofen on gait score, but reported

Table 1. Results of logistic regression of a cow being lame (numerical rating system, NRS $>3$ ) or not using several measures of weight distribution $(\mathrm{n}=57)$ and of activity $(\mathrm{n}=52)$ as predictors

\begin{tabular}{llllll}
\hline Variable & $\mathrm{OR}^{1}$ & $95 \% \mathrm{CI}$ & $\mathrm{AUC}^{2}$ & $\mathrm{R}^{2}$ & $P_{\text {Wald }}$ \\
\hline SD of the rear legs (kg) & $1.39^{3}$ & $1.08-1.81$ & 0.71 & 0.17 & 0.02 \\
SD of the front legs (kg) & $1.58^{3}$ & $1.08-2.34$ & 0.69 & 0.16 & 0.02 \\
Leg weight ratio of rear legs & $0.67^{4}$ & $0.50-0.91$ & 0.69 & 0.22 & 0.001 \\
Daily lying time (min) & $1.14^{5}$ & $0.99-1.3$ & 0.64 & 0.09 & 0.07 \\
Lying bout duration (min) & $1.46^{5}$ & $1.05-2.02$ & 0.65 & 0.17 & 0.01 \\
Walking speed (m/s) & $0.69^{6}$ & $0.54-0.89$ & 0.73 & 0.22 & 0.004 \\
\hline
\end{tabular}

${ }^{1}$ Odds ratio.

${ }^{2}$ Area under the receiver operating characteristics curve.

${ }^{3} \mathrm{OR}$ adjusted to a $5-\mathrm{kg}$ increase.

${ }^{4} \mathrm{OR}$ adjusted to a $5 \%$ increase in the rear leg weight ratio.

${ }^{5} \mathrm{OR}$ adjusted to a 30-min increase.

${ }^{6} \mathrm{OR}$ adjusted to a $0.1 \mathrm{~m} / \mathrm{s}$ increase. 
a modulation in hyperalgesia associated with lameness in cows injected with ketoprofen, and not with saline. Thus, subjective gait scoring proved less sensitive in detecting treatment effects than the nociceptive threshold test.

A greater SD of weight applied to the rear legs in lame cows was found, supporting results of previous studies (Pastell and Kujala, 2007; Rushen et al., 2007), and this measure was the most accurate in identifying lame cows. This measure shows the variability in weight applied to a leg over time and indicates the amount of weight shifting that occurred. A lower LWR was found in the rear legs in lame cows, supporting Pastell and Kujala (2007). This measure is an indicator of asymmetry within each pair of legs. Lame cows are reluctant to bear weight on the afflicted leg and therefore, they favor the contralateral leg. A moderate effect of ketoprofen was found on the SD of the rear legs; that is, ketoprofen decreased weight shifting between the rear legs. This was observed both for cows categorized as lame and for those categorized as nonlame based on gait scoring. The effect in cows classified as nonlame may be because of some imperfections in locomotion. Rushen et al. (2007) found a decrease of the SD of the injured leg and the contralateral leg of $25 \mathrm{~kg}$ (a more than $50 \%$ decrease) following injections of local anesthetic. Cows in that study scored $\geq 4$ and had a severe lesion in the hoof. The effect found here was less, probably because cows were not as lame and because lidocaine blocked the nerve and, therefore, had a more specific and localized effect on the lesion identified as the cause of pain.

Lame cows had longer lying bouts, supporting results from other studies (Singh et al., 1993; Walker et al., 2008; Chapinal et al., 2009b). There were no differences between lame and nonlame cows in the frequency of steps, whereas O'Callaghan et al. (2003) found that lame cows made fewer steps (71.8 vs. 94.3 steps/h). Variability between cows in lying time is very high (Ito et al., 2009), and it is sometimes difficult to find differences between lame and nonlame cows using activity measures. Lying behavior and frequency of steps failed to show an analgesic effect of ketoprofen.

The frequencies of steps reported by O'Callaghan et al. (2003) were higher than found here (61 steps/h), but it could be due in part to removal for $3 \mathrm{~h} / \mathrm{d}$ from the most active time of day, to avoid the confounding effect of experimental procedures.

Lame cows walked slower than nonlame cows, and walking speed was a good predictor of lameness. The values of walking speed supported results of Flower et al. (2007) and Chapinal et al. (2009a,b). Flower et al. (2005, 2006) and O'Callaghan et al. (2003) reported that lame cows with ulcers walked more slowly than

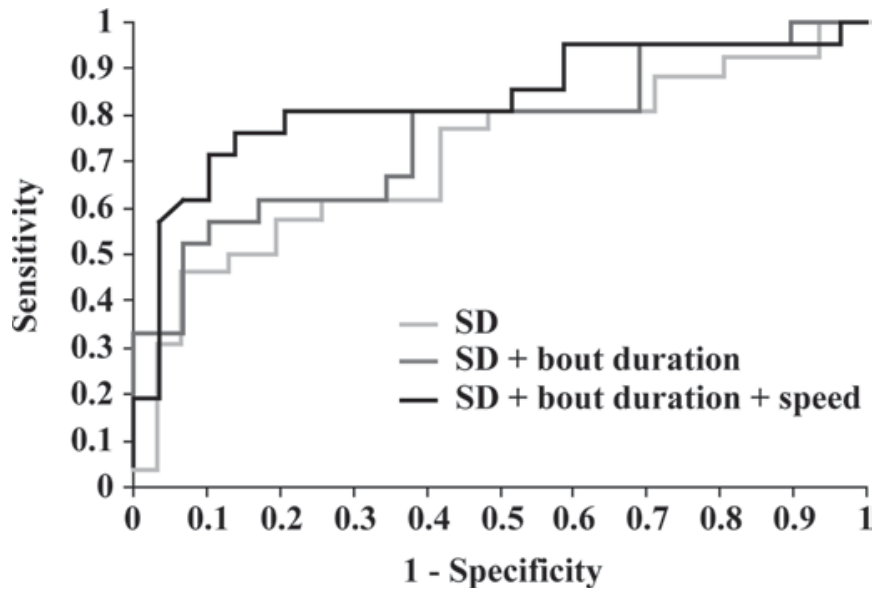

Figure 2. Receiver operating characteristics curve for different logistic regression models to discriminate between lame (numerical rating system, NRS $>3$ ) and nonlame cows, including as predictor a) only the SD of the weight applied to the rear legs $(\mathrm{AUC}=0.71)$; $\mathrm{b})$ the SD of the weight applied to the rear legs and the average duration of the lying bout $(\mathrm{AUC}=0.76$ ), and c) the SD of the weight applied to the rear legs, the average duration of the lying bout, and walking speed $(\mathrm{AUC}=0.83) . \mathrm{AUC}=$ area under the curve.

cows without lesions, although Flower et al. (2007) and Chapinal et al. (2009b) found no differences. With time, walking speed decreased regardless of the treatment and lameness condition, probably because of habituation to the procedure. Therefore, caution is needed when using walking speed for lameness detection.

With herds becoming larger and technology more available, a combination of automated methods of lameness detection could become a practical solution for on-farm lameness detection and for monitoring treatment effectiveness and recovery. A combination of weight distribution, lying bout duration, and walking speed was the best at predicting lameness. Although the SD of the rear legs was one of the best measures, the accuracy increased when this was combined with measures of lying bout duration and walking speed.

In conclusion, measures of weight shifting between legs while cows are standing, lying behavior, and walking speed show great potential as automated methods of detecting lameness and evaluating lameness therapies. Ketoprofen reduced the effects of lameness on weight shifting, but had no other behavioral effects.

\section{ACKNOWLEDGMENTS}

We thank Molly Ronning, Pilar Sepúlveda, João Henrique H. Costa, Camilo Díaz, Gosia Zdanowicz, Sue Vickers, and all the staff at The University of British Columbia Dairy Education and Research Centre. The project was supported by the National Research Initiative of the USDA National Institute of Food and 
Agriculture, grant number 2008-35204-04607, the Animal Global Partnerships (formerly Animal Compassion Foundation), and Agriculture and Agri-Food Canada.

\section{REFERENCES}

Borderas, T. F., A. R. Fournier, J. Rushen, and A. M. de Passillé. 2008. Effect of lameness on dairy cows' visits to automatic milking systems. Can. J. Anim. Sci. 88:1-8.

Chapinal, N., A. M. de Passille, and J. Rushen. 2009a. Weight distribution and gait in dairy cattle are affected by milking and late pregnancy. J. Dairy Sci. 92:581-588.

Chapinal, N., A. M. de Passillé, D. M. Weary, M. A. G. von Keyserlingk, and J. Rushen. 2009b. Using gait score, walking speed, and lying behavior to detect hoof lesions in dairy cows. J. Dairy Sci. 92:4365-4374.

Espejo, L. A., and M. I. Endres. 2007. Herd-level risk factors for lameness in high-producing Holstein cows housed in freestall barns. J. Dairy Sci. 90:306-314.

Flower, F. C., A. M. de Passillé, D. M. Weary, D. J. Sanderson, and J. Rushen. 2007. Softer, higher-friction flooring improves gait of cows with and without sole ulcers. J. Dairy Sci. 90:1235-1242.

Flower, F. C., D. J. Sanderson, and D. M. Weary. 2005. Hoof pathologies influence kinematic measures of dairy cow gait. J. Dairy Sci. 88:3166-3173.

Flower, F. C., D. J. Sanderson, and D. M. Weary. 2006. Effects of milking on dairy cow gait. J. Dairy Sci. 89:2084-2089.

Flower, F. C., M. Sedlbauer, E. Carter, M. A. von Keyserlingk, D. J. Sanderson, and D. M. Weary. 2008. Analgesics improve the gait of lame dairy cattle. J. Dairy Sci. 91:3010-3014.

Flower, F. C., and D. M. Weary. 2006. Effect of hoof pathologies on subjective assessments of dairy cow gait. J. Dairy Sci. 89:139 146.

Ito, K., D. M. Weary, and M. A. G. von Keyserlingk. 2009. Lying behavior: Assessing within- and between-herd variation in freestall-housed dairy cows. J. Dairy Sci. 92:4412-4420.

Lees, P., M. F. Landoni, J. Giraudel, and P. L. Toutain. 2004. Pharmacodynamics and pharmacokinetics of nonsteroidal anti- inflammatory drugs in species of veterinary interest. J. Vet. Pharm. Ther. 27:479-490.

Munksgaard, L., C. G. Reenen, and R. Boyce. 2006. Automatic monitoring of lying, standing and walking behavior in dairy cattle. J. Dairy Sci. 84(Suppl. 1):304. (Abstr.)

Neveux, S., D. M. Weary, J. Rushen, M. A. von Keyserlingk, and A. M. de Passillé. 2006. Hoof discomfort changes how dairy cattle distribute their body weight. J. Dairy Sci. 89:2503-2509.

NRC. 2001. Nutrient Requirements of Dairy Cattle. 7th rev. ed. National Academy Press, Washington, DC.

O'Callaghan, K. A., P. J. Cripps, D. Y. Downham, and R. D. Murray. 2003. Subjective and objective assessment of pain and discomfort due to lameness in dairy cattle. Anim. Welf. 12:605-610.

Owens, J. G., S. G. Kamerling, S. R. Stanton, and M. L. Keowen. 1995. Effects of ketoprofen and phenylbutazone on chronic pain and lameness in the horse. Equine Vet. J. 27:296-300.

Pastell, M. E., and M. Kujala. 2007. A probabilistic neural network model for lameness detection. J. Dairy Sci. 90:2283-2292.

Rushen, J., A. M. de Passillé, M. A. G. von Keyserlingk, and D. M. Weary. 2008. The Welfare of Cattle. Springer Netherlands, Dordrecht, the Netherlands.

Rushen, J., E. Pombourcq, and A. M. d. Passillé. 2007. Validation of two measures of lameness in dairy cows. Appl. Anim. Behav. Sci. 106:173-177.

SAS Institute. 2003. SAS User's Guide. SAS Institute Inc., Cary, NC.

Singh, S. S., W. R. Ward, K. Lautenbach, and R. D. Murray. 1993. Behaviour of lame and normal dairy cows in cubicles and in a straw yard. Vet. Rec. 133:204-208.

Walker, S. L., R. F. Smith, J. E. Routly, D. N. Jones, M. J. Morris, and H. Dobson. 2008. Lameness, activity time-budgets, and estrus expression in dairy cattle. J. Dairy Sci. 91:4552-4559.

Whay, H. R., A. E. Waterman, A. J. F. Webster, and J. K. O'Brien. 1998. The influence of lesion type on the duration of hyperalgesia associated with hind limb lameness in dairy cattle. Vet. J. 56:2329.

Whay, H. R., A. J. F. Webster, and A. E. Waterman-Pearson. 2005. Role of ketoprofen in the modulation of hyperalgesia associated with lameness in dairy cattle. Vet. Rec. 157:729-733. 